\title{
Sustainability of groundwater resources in India: challenges and scope for economic instruments and policy
}

\author{
S. Msangi \\ International Food Policy Research Institute, Washington DC, USA
}

\begin{abstract}
In this paper we address the groundwater resource management issues in selected regions of India, within the context of the policy and natural environments that exist. We illustrate the underlying nature of the resource management problem, and suggest possible alternative interventions, with the use of an economic model that is linked to a simplified representation of the characteristic hydrology. By illustrating the policy problem in this way, the paper explores the scope that alternative economic instruments could have in correcting the perverse incentives that exist for groundwater conservation, in some regions, while improving human welfare. In doing so, we hope to better clarify the role of market (and non-market based) instruments in addressing common pool resource management problems in India, and provide guidance to researchers and policy makers on how they can best study these cases, and further refine their policy recommendations
\end{abstract}

Keywords: groundwater, common pool resources, policy and institutions, market-based instruments, natural resource management.

\section{Introduction}

The importance of irrigation in maintaining the necessary productivity within the Indian agricultural sector has long been recognized by researchers and policy makers, and is a major driver behind the growth in output that was observed during the period of the 'Green Revolution'. While the agro-ecological conditions vary widely across the Indian sub-continent, there is a sizable share of agricultural production that relies on irrigation, as is shown in Table 1, below. 
Table 1: $\quad$ India Irrigation, 2003-2004.

\begin{tabular}{||cccc||}
\hline State & $\begin{array}{c}\text { Total Cultivable Area } \\
\text { ('000 ha) }\end{array}$ & $\begin{array}{c}\text { Net Irrigated Area } \\
\text { ('000 ha) }\end{array}$ & $\begin{array}{c}\text { Irrigated as \% of } \\
\text { Total Cultivable }\end{array}$ \\
\hline \hline East & 13,077 & 2,416 & $18.5 \%$ \\
West & 76,758 & 16,862 & $22.0 \%$ \\
North Central & 36,529 & 18,977 & $52.0 \%$ \\
North East & 6,129 & 439 & $7.2 \%$ \\
North West & 11,477 & 7,818 & $68.1 \%$ \\
South & 39,498 & 8,592 & $21.8 \%$ \\
& & & $30.0 \%$ \\
All India Total & 183,468 & 55,104 & \\
\hline
\end{tabular}

Source: CWC, Delhi, India - Water Related Statistics.

The deepening scarcity problems that have been observed in many parts of India, as a result of increasing demands on limited water resources for both agricultural and non-agricultural uses, has also been a source of concern for both policy makers and analysts who seek to promote the sustainability of water resources through improved management on both the demand and the supply side.

Much of the literature that deals with the management of water resources in Indian agriculture has focused, in particular, on groundwater management, which represents a significant share of the water resources that are available to the majority of Indian farmers. Table 2, below, shows the agricultural area that is supported by tubewells and other wells, as opposed to other kinds of water withdrawals from surface sources.

Table 2: $\quad$ Indian Irrigation by Source ('000 ha).

\begin{tabular}{|c|c|c|c|c|}
\hline State & $\begin{array}{l}\text { Tube } \\
\text { Wells }\end{array}$ & $\begin{array}{l}\text { Other } \\
\text { Wells }\end{array}$ & $\begin{array}{l}\text { Other } \\
\text { Sources }\end{array}$ & $\begin{array}{l}\text { Total All } \\
\text { Sources }\end{array}$ \\
\hline East & 233 & 98 & 265 & 2,416 \\
\hline West & 3,865 & 8,220 & 893 & 16,867 \\
\hline North Central & 12,898 & 569 & 622 & 18,977 \\
\hline North East & 2 & 2 & 193 & 437 \\
\hline North West & 4,865 & 20 & 183 & 7,818 \\
\hline South & 2,304 & 2,186 & 597 & 8,592 \\
\hline All India Total & 24,167 & 11,095 & 2,753 & 55,107 \\
\hline
\end{tabular}

Source: CWC, Delhi, India - Water Related Statistics.

The deepening scarcity problems that have been observed in many parts of India, as a result of increasing demands on limited water resources for both agricultural and non-agricultural uses, has also been a source of concern for both policy makers and analysts who seek to promote the sustainability of water 
resources through improved management on both the demand and the supply side. A number of authors have focused upon the electricity subsidies to agriculture, which might be giving perverse incentives to farmers using electric pumps to withdraw more groundwater than would otherwise be socially optimal $[3,6]$. Others have suggested alternative policy instruments that might help groundwater users to internalize the external effects that they impose upon other users of the common-pool groundwater resource, through such instruments as taxes on pumping, based either on the volumetric quantity of water used or electricity that is consumed [4].

These types of instruments, however, are difficult to impose, due to problems of observability and measurability of actual volumes of water that are used by individual groundwater users. The recommendations that might apply to regions which have groundwater pumpers with very large landholdings, like Kern County, California [1], may not be as applicable to developing country regions where there are numerous small-holder farmers, like in East and South Asia. A number of other studies have tried to examine the role of markets for water, and how they can potentially improve the allocation of water among users, by using market-based incentives and trading mechanisms, as well as the possible welfare losses that can result from the exercise of monopoly power by wealthier and larger landowners on their poorer and smaller neighbours [2,5].

In this paper, however, we will focus on the choice of instruments that might be employed by policy makers to encourage more efficient use of water resources, and promote the sustainability of limited groundwater resources, within the context of India. We will consider the efficacy of tax- or tarrif-based approaches to control, as well as that of quantity-focused instruments - and discuss the situations in which the efficacy of one might outweigh that of the alternative methods. We will discuss these instruments within the context of a theoretical model of economic behaviour, which addresses both groundwater use as well as inter-agent re-allocation and trade of permits. Our conclusions and recommendations will then close the paper.

\section{Economic behaviour in water usage}

The economics of water usage is typically based upon the behavioural economics of a profit-maximizing agent, who seeks to maximize the net revenue that accrues from irrigated agricultural production, and faces a trade-off in terms of costs of inputs (including water), or constraints in water or land use. Even without considering the dynamics of groundwater usage, and how the stock of water held in the underground aquifer evolves over time, the individual profitseeking agent can be hypothesized to behave according to the following, simple maximization problem.

$$
\max _{x, A} p A f(x)-c x-\alpha A^{2} \quad \text { s.t. } \quad A \leq \bar{A}
$$

where the decision-maker's problem is defined in terms of choosing the optimal level of input (i.e. water) which enters into the agricultural yield function $f(x)$, 
while also choosing the optimal land area over which to farm, $A$, which is available up to a particular limit $\bar{A}$. The price of the agricultural output is denoted by $p$, whereas the cost of the productive input is given as $c$. The quadratic term in land area, $\alpha$, captures the decreasing returns to adding land area which is due to limited management and labour, as well as variable land quality over the available area. The maximization problem written in eqn (1) can be stated in terms of the full Lagrangian function, shown in eqn (2) below, which has the shadow value of the constraint included as a choice variable

$$
\max _{x, A, \lambda} L(x, A, \lambda)=p A f(x)-c x-\alpha A^{2}-\lambda[A-\bar{A}]
$$

The necessary conditions for profit-maximizing choice over the variables $x$ and $A$, lead to the following set of equations

$$
\begin{array}{lll}
p A f^{\prime}(x)-c \leq 0 & x \geq 0 & x\left[p A f^{\prime}(x)-c\right]=0 \\
p f(x)-2 \alpha A-\lambda \leq 0 & A \geq 0 & A[p f(x)-2 \alpha A-\lambda]=0 \\
A-\bar{A} \leq 0 & \lambda \geq 0 & \lambda[A-\bar{A}]=0
\end{array}
$$

which we can use to define the optimal choice of water and land usage by the representative farmer. If we were to assume that the decision-maker always chooses to use as much land as is available, then we can reduce the set of conditions in eqn (3) to the following pair of equations

$$
\begin{aligned}
& p \bar{A} f^{\prime}(x)-c=0 \\
& p f(x)-2 \alpha \bar{A}-\lambda=0
\end{aligned}
$$

which we can use to examine the sensitivity of the optimal choices to the key economic parameter values. By totally differentiating the pair of first-order conditions in eqn (3), with respect to each variable and parameter, we obtain the following linear system

$$
\left[\begin{array}{cc}
p \bar{A} f^{\prime \prime}(x) & 0 \\
p f^{\prime}(x) & -1
\end{array}\right]\left[\begin{array}{l}
d x \\
d \lambda
\end{array}\right]=\left[\begin{array}{ccc}
-\bar{A} f^{\prime}(x) & -p f^{\prime}(x) & +1 \\
-f(x) & +2 \alpha & 0
\end{array}\right]\left[\begin{array}{c}
d p \\
d \bar{A} \\
d c
\end{array}\right]
$$

which allows us to relate changes in the vector of decision variables, on the left hand side, to the vector of the key parameters, on the right hand side. The sign of the principle determinant, $\mathrm{D}$, shown below

$$
D=\left|\begin{array}{cc}
p \bar{A} f^{\prime \prime}(x) & 0 \\
p f^{\prime}(x) & -1
\end{array}\right|>0
$$

conforms to our expectations of a well-behaved maximization problem, in which the set of production possibilities can be circumscribed by a convex hull. Applying Cramer's rule to the linear system in eqn (5), allows us to perform the following comparative static calculations, in which we examine the impact of parameter changes on the key decision variable of interest - that of water use 
( $x$ ). In order to look at the impact of changes in the volumetric cost of water $(c)$ on water usage, we can compute the following differential

$$
\frac{\partial x}{\partial c}=\frac{\left|\begin{array}{cc}
+1 & 0 \\
0 & -1
\end{array}\right|}{D}=\frac{-1}{D}<0
$$

in which the marginal effect of increasing the cost, serves to decrease the level of water usage, as we would expect. Similarly, we can examine the impact of changing the constraint on land, such that we allow for a marginal change in the binding quantity $\bar{A}$.

$$
\frac{\partial x}{\partial \bar{A}}=\frac{\left|\begin{array}{cc}
-p f^{\prime}(x) & 0 \\
+2 \alpha & -1
\end{array}\right|}{D}=\frac{p f^{\prime}(x)}{D}>0
$$

while these effects are opposite in sign, we can see that their relative magnitude depends on the magnitude of the value marginal product of water $p f^{\prime}(x)$ relative to unity. If it turns out that the value marginal product exceeds unity, then a change in allowable land area might be more effective in reducing water usage, than a change in the unit variable cost of water. The converse would be implied by the case where $p f^{\prime}(x)<1$. While the comparison of marginal impacts on water use, from the point of view of comparative statics is useful in judging the efficacy of alternative instruments for managing water demand - it does not describe the relative efficacy of the institutions that might be used to apply those instruments. We will now take up this discussion, in the following section.

\section{Institutional efficacy of economic instruments}

Now that we have discussed the technical aspects of groundwater user behaviour, with respect to key parameters of economic behaviour, we can now turn to the institutional aspects of implementing groundwater management policy. The unit cost of water usage, which we described by the single parameter $c$, in eqns (1) and (2), can be conceptualized as a function of several variables, within the context of groundwater usage. Typically, the marginal cost of groundwater pumping is thought to vary according to the hydrological conditions under which water is withdrawn from the aquifer. In particular, the distance over which water must be lifted from the groundwater table to the surface (i.e. the 'lift') is a key determinant to the marginal cost of pumping a single volumetric unit of water, as well as the energy costs that are associated with the action of the pump. Therefore, we can describe the marginal cost of water as a function of the 'state' of the system, which we can describe by the state variable $h$, which denotes the height of the groundwater table with respect to a reference level, and the distance it lies below the ground surface $\bar{S}$, shown in Figure 1 below. 


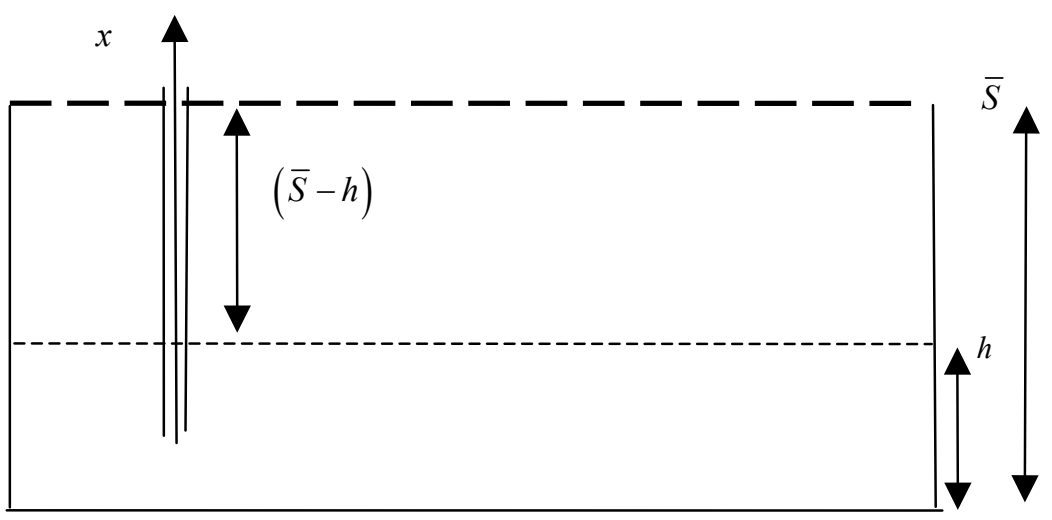

Figure 1: Simplified representation of pumping from an aquifer.

Combining the 'lift' $(\bar{S}-h)$ with the energy cost of pumping $(e)$, we can express the marginal cost of water usage as

$$
c(h, e)=\gamma e \cdot(\bar{S}-h)
$$

where $\gamma$ is a conversion factor.

\subsection{Alternative economic instruments for demand management}

If we were to introduce a volumetric charge for pumping, then this would act as an additive factor that raises the marginal cost of pumping above that which is determined by energy and the hydrological state of the system. Such a charge or tax, $t$, would change the marginal cost in eqn (9) to equal

$$
\tilde{c}(h, e, t)=\gamma e \cdot(\bar{S}-h)+t
$$

If we were to use the upper limit on available land as a policy instrument that limits the area of a heavily water-consumptive crop - we could then specify a limit that either coincides with or falls below the "natural' limit that the farmer would otherwise face in the absence of policy intervention. If we denote this limit as a quota $(\bar{Q})$, which would be allocated to each irrigator, then we would have

$$
\max _{x, A} \quad p A f(x)-c(h, e, t) x-\alpha A^{2} \quad \text { s.t. } \quad A \leq \bar{Q} \leq \bar{A}
$$

which represents the modified maximization problem of the irrigator who faces two possible policy instruments. Applying the same assumptions as those used to derive eqn (4), we would have a modified set of first-order necessary conditions

$$
\begin{aligned}
& p \bar{Q} f^{\prime}(x)-\gamma e \cdot(\bar{S}-h)+t=0 \\
& p f(x)-2 \alpha \bar{Q}-\lambda=0
\end{aligned}
$$


which yields a similar linear equation system, when we take the total differentials with respect to all the decision variables and parameters of the problem. The magnitude of the differential, with respect to the tax, is identical to that shown in eqn (7), and is only a function of the parameters in the determinant. We can derive an additional expression that illustrates the impact of the quota on the implicit shadow value $\lambda$, which can be written as

$$
\frac{\partial \lambda}{\partial \bar{Q}}=\frac{2 \alpha p \bar{Q} f^{\prime \prime}(x)+(\tilde{c} / \bar{Q})^{2}}{D}<0
$$

and is negative in sign, if the marginal pumping cost is sufficiently small compared to the allocated quota. The sign of this expression conforms to what we would expect from a downward sloping demand curve for allocated quota, and denotes that the willingness to pay for additional quota goes up as the allocation gets smaller.

In the hands of a well-informed agent, who is forward-looking with respect to the state of the groundwater table, and the implications that a lower water table has for the future pumping costs and producer welfare - we could construct an optimal path of extraction that would ensure the long-term efficiency of water usage, and maximize the sustainability of groundwater usage. Such a path would be obtained by solving the following social planner's problem.

$$
V^{C P}(h)=\max _{x, A}\left\{\begin{array}{l}
p A f(x)-\gamma e \cdot(\bar{S}-h) x-\alpha A^{2}+\beta V^{C P}(h+\varphi x-\tilde{r}) \\
\text { s.t. } \quad A \leq \bar{A}
\end{array}\right\}
$$

where the inter-temporal optimization is carried out with respect to the pumping of all players in each period, and where $\beta$ is the discount rate that captures the social planners inter-temporal preferences. The function $V(h)$ is the maximized value of the dynamic game problem, for each player, beginning with the current level of groundwater lift $(h)$, and proceeding under the assumption that actions taken in subsequent periods are done optimally with respect to the groundwater lift in each period. This recursive relationship linking the implied optimality of behavior from period-to-period captures the essence of Bellman's "Principle of Optimality" (Bellman, 1957).

The solution to the social planner's problem would give a 'benchmark' outcome for water and land use that would maximize long-run benefits over time, and enhance groundwater resource sustainability over time. This benchmark would guide the policy maker as to the best choice of tax $(\hat{t})$ or quota $(\hat{Q})$ to impose as an economic instrument on the less-informed, myopic irrigator who would not otherwise consider the long-run benefit. Where numerous irrigators are involved, the social planners problem can be generalized to yield a vector of decisions over all agents that prescribe their optimal pumping $\left\{\hat{x}_{i}\right\}_{i=1}^{N}$ and land use $\left\{\hat{A}_{i}\right\}_{i=1}^{N}$ behaviour, over time. The well-informed policymaker would choose the optimal quota allocations as $\hat{Q}_{i}=\hat{A}_{i}$ and the optimal 
pumping tax $(\hat{t})$ equal to $\beta V^{\prime}(h+\varphi x-\tilde{r})$, which represents the extra marginal cost that the social planner imputes to each unit of water withdrawn from the aquifer, and is proportional to the derivative of the optimal value function.

The information that would be needed by the policy maker to set these policy instruments to their optimal levels is daunting, when dealing with many individual agents, and is beyond the capacity of typical institutions of groundwater management. The fact that the individual irrigators know their own technologies and productive possibilities much better than the central administrator is a persuasive argument behind using market-based instruments such that the individuals can interact within a decentralized framework, on the basis of their privately-held information.

\subsection{Market-based instruments for demand allocation}

Allowing the quotas for land area to be tradeable, allows each player to engage in decentralized transactions that allow them to trade their initial allocations up to the point that their private benefits are maximized, and their individual shadow values for quota allocations $\left(\lambda_{i}\right)$, are equalized across agents. Taking the case of just two agents into consideration, for simplicity, we can depict such an equilibrium outcome in terms of Figure 2, below. This figure shows the equilibrium outcome where transaction costs exist $(\tau)$, which cause the agent transactions $(\hat{z})$ to deviate from those levels that would be realized in the absence of transaction costs $\left(z^{*}\right)$. In the presence of transactions costs, the volume of trade is less than that which is otherwise, achievable, and the aggregate benefits of both agents fall below that which the central planner could achieve in the benchmark case.

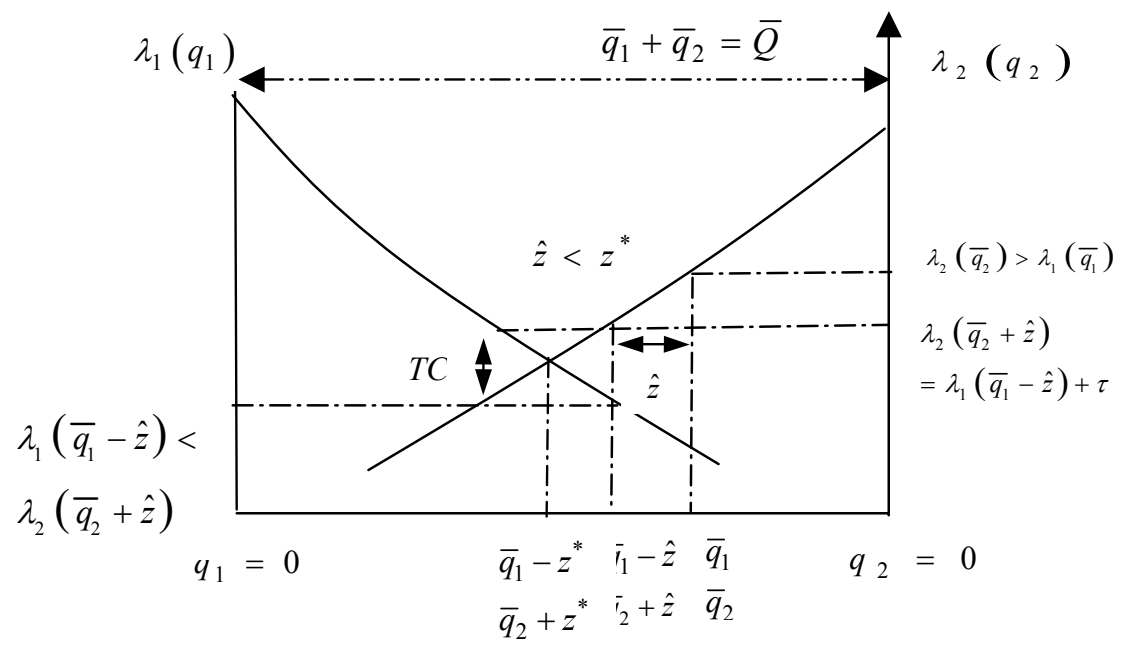

Figure 2: Decentralized allocation of tradable quota between agents. 


\section{Tradeoffs between alternative policy instruments}

This represents a common trade-off that is faced by policy makers, when implementing market-based instruments to improve the efficiency of decentralized schemes for resource allocation. The excessive information requirements of implementing an optimal tax on volumetric extraction - both in terms of monitoring the volumes of water extracted by each individual and deciding on the welfare-maximizing level across all agents - has to be balanced against the likely transaction costs that would be incurred by the individual agents who try and enact trades within a decentralized framework.

It remains an empirical matter to determine how large the loss of welfare due to transaction costs are, within a decentralized allocation scheme, relative to the administrative 'errors' that would be incurred by implementing a centralized allocation of quota with imperfect information. The advantage of allocating land areas, from an administrative point of view, lies in the fact that it is much easier to observe land area and cropping patterns, than it is to observe individual volumetric quantities of water withdrawal. So by replacing the taxing of groundwater pumping with the restriction of land area, based on the type of crop that is grown - such that more water-consuming crops can be limited to a maximum area - we can overcome some of the information problems that would otherwise face the regulator in implementing a demand management scheme over many irrigators.

\section{Conclusions}

In this paper, we have discussed the relative effectiveness of price-based instruments that increase the volumetric cost of water, compared to a quantitybased limit on available land, within the context of a profit-maximizing irrigator. We have argued for the relative efficacy of these instruments, on the basis of the transaction and administrative costs that might be incurred in their implementation, either within a centralized or decentralized scheme of water demand management. We conclude that quantity-based instruments are more easily observable, and might impact total consumptive use of water within a groundwater basis to a greater degree than price-based instruments that only act to reduce water withdrawals from the common pool resource. Despite the welfare losses that are inevitable, when implementing market-based schemes for decentralized demand management, these might still serve to overcome problems of asymmetric information that will inevitably occur when a lessinformed central administrator faces a large number of individual irrigators. The degree to which these transaction costs might reduce the efficacy below that of a 'naïve' implementation scheme by a central regulator, remains a question that can only be answered by further empirical work. The importance of irrigation to Indian agriculture, warrants such research, as it will undoubtedly enhance the knowledge base that policy makers need to have to better promote the sustainability of India's limited and increasingly stressed water resources. 
82 Sustainable Irrigation Management, Technologies and Policies II

\section{References}

[1] Feinerman, E. \& Knapp, K.C., Benefits from groundwater management: Magnitude, sensitivity and distribution. American Journal of Agricultural Economics, 65, pp. 703-710, 1983.

[2] Kajisa, K. \& Sakurai, T., Efficiency and Equity in groundwater markets: The case of Madhya Pradesh, India. Environment and Development Economics, 10(6), pp. 801-819, 2005.

[3] Kumar, M.D., Impact of electricity prices and volumetric water allocation on energy and groundwater demand management: Analysis from western India. Energy Policy, 33(1), pp. 39-51, 2005.

[4] Kumar, M.D. \& Singh, O.P., Market instruments for demand management in the face of scarcity and overuse of water and Gujarat, western India. Water Policy, 3, pp. 387-403, 2001.

[5] Prakash, A., The dark zone. Orient Longman: New Delhi, pp. 75-100, 2005.

[6] Scott, C.A. \& Shah, T., Groundwater overdraft reduction through agricultural energy policy: Insights from India and Mexico. Water Resources Development, 20(2), pp. 149-164, 2004. 